\title{
DEMOCRACIA Y PLURALISMO MORAL
}

\section{DEMOCRACY AND MORAL PLURALISM}

\author{
(iD) Miguel Ángel Polo Santillán ${ }^{{ }^{*}}$ \\ mpolos1@unmsm.edu.pe \\ ${ }^{1}$ Universidad Nacional Mayor de San Marcos, Lima, Perú
}

*Correspondencia: Miguel Ángel Polo Santillán. Email: mpolos1@unmsm.edu.pe

Recibido: 15.02.2020 | Aprobado: 12.03.2020

\section{RESUMEN}

En julio del año pasado, la fiscalía pidió al decano de la Facultad de Letras de la UNMSM informe sobre unas conferencias cuyo tema había sido el marxismo. Sin duda, esto estaba fuera de lugar, si consideramos que vivimos en una democracia. Quizá todavía son temores de los años 80 y 90, del siglo pasado, dado que el grupo terrorista Sendero Luminoso estaba alimentado por el marxismo, interpretado por su líder. Esto llevó a la caza de brujas en los años 90, pues todo estudiante o profesor que tuviese libros de marxismo era considerado senderista o terrorista. En esta breve reflexión nos interesa pensar la relación entre democracia y pluralismo, de ideas y prácticas, dentro del límite de los derechos humanos. Pues, en estos tiempos, nuevas olas de fundamentalismo y limitaciones a la libertad de pensamiento y expresión se dan en todo el mundo.

Palabras clave: Democracia, Pluralismo, Moral.

\section{ABSTRACT}

In July of last year, the prosecutor's office asked the dean of the Faculty of Letters of the UNMSM to report on some conferences whose theme had been Marxism. This was certainly out of the question, considering that we live in a democracy. Perhaps they are still fears from the 1980s and 1990s, given that the Shining Path terrorist group was fueled by Marxism, played by its leader. This led to the witch hunt in the 1990s, as any student or teacher who had books on Marxism was considered a Shining Path or a terrorist. In this brief reflection we are interested in thinking about the relationship between democracy and pluralism, of ideas and practices, within the limits of human rights. Well, in these times, new waves of fundamentalism and limitations on freedom of thought and expression are taking place all over the world.

Keywords: Democracy, Pluralism, Moral. 


\section{EL ENFOQUE LIBERAL DE LA RELACIÓN ENTRE DEMOCRACIA Y PLURALISMO}

Hoy hablamos de democracias liberales, aunque ya hemos dicho que no siempre los liberales han sido demócratas ni toda democracia ha sido liberal. Si hablamos de democracia es porque asumimos que es una forma de gobierno - por lo menos en ideal, pero que debe ser realizado - del pueblo, para el pueblo y por el pueblo. Sin embargo, nuestras sociedades contemporáneas no son homogéneas, sino muy diversas axiológicamente, expresadas en distintas expresiones artísticas, religiosas, morales y de saberes. Diversidad que tiene que ver con sus historias y tradiciones particulares. El liberalismo político considera necesaria esa libertad para el crecimiento de las personas y los grupos, siempre que no dañe a los demás, especialmente en su integridad física o psicológica. Así, un Estado democrático no debiera perseguir a ninguna expresión del pensamiento humano, por más absurda o irracional que nos parezca. Mill (1997), en el siglo XIX, lo pondrá claramente:

"Que la única finalidad por la cual el poder puede, con pleno derecho, ser ejercido sobre un miembro de una comunidad civilizada contra su voluntad, es evitar que perjudique a los demás. Su propio bien, físico o moral, no es justificación suficiente. Nadie puede ser obligado justificadamente a realizar o no realizar determinados actos, porque eso fuera mejor para él, porque le haría feliz, porque, en opinión de los demás, hacerlo sería más acertado o más justo. Estas son buenas razones para discutir, razonar y persuadirle, pero no para obligarle o causarle algún perjuicio si obra de manera diferente." (p. 94)

Así, ni la sociedad en su conjunto ni el Estado, debieran obligar a los ciudadanos a pensar de una manera determinada, creyendo que esa es la única manera buena y correcta de pensar. Si lo hace, entonces deja de ser democracia, convirtiéndose en dictadura o totalitarismo. Las dictaduras militares latinoamericanas de los 70 persiguieron, asesinaron y desaparecieron a los opositores políticos. Los gobiernos llamados comunistas como el soviético y de "socialismo real", también hicieron lo mismo. Y la historia de gobiernos y sociedades intolerantes con creencias e ideas se pierde en la historia humana. Por eso, una sociedad democrática debe estar en guardia contra todo intento dictatorial o totalitario, del signo que sea, pues tiende a anular violentamente las diferencias.

¿Qué hacer entonces con las diferencias? Pues procesarlas en espacios públicos, que no puede ser solo el congreso, sino también los medios de comunicación y las universidades. Abrir más espacios de debate, de diálogo, de confrontación de ideas, y no solo de prédica ideológica que busca convertir a los ciudadanos a un determinado color y negando el valor de los demás. Las universidades no solo son centros de preparación de profesionales para el mercado laboral, sino espacios públicos de debates de ideas, revisando su racionalidad y desiderátum. ¿A esto apuntan nuestras prácticas universitarias? Después de todo, los fiscales han salido de las universidades, por lo que también algo está diciendo sobre nuestras propias instituciones académicas.

\section{EL ENFOQUE MORAL DEL PLURALISMO}

El enfoque liberal se centra en la libertad, pero en nuestros días necesitamos perspectivas más enriquecedoras, pues este valor también ha pasado a encubrir injusticias 
sociales. Reiteramos que las sociedades no son homogéneas, por lo que requieren de espacios públicos de debates no solo para solucionar sus conflictos, sino para ir encontrando mínimos de convivencia social. Este es el enfoque moral, que se opone a toda forma totalitaria o mesiánica que solo traen violencia. Por eso, ya el diálogo mismo es un valor que deberíamos promover mucho más, antes que solo censurar reactivamente. Somos seres que usamos el lenguaje para todo lo que buscamos, ¿por qué no debiera servirnos para entendernos? Cuando nos sentamos a conversar y solo nos burlamos o insultamos o gritamos o amenazamos, todo eso no es practicar el diálogo.

Ni homogeneidad violenta ni caos agresivo de apuestas ideológicas, necesitamos el término medio del pluralismo moral, que reconoce nuestras diferencias, pero también la necesidad de mínimos morales para convivir. Y eso no lo puede decidir el Estado, solo abrir ese campo de discusión orientado por el horizonte del país que buscamos, uno que sea bueno y justo para con todos los ciudadanos. Así, la bondad (bienestar) y justicia son otros valores indispensables en nuestra convivencia. Y si queda claro que todos queremos un mejor país, entonces, será la solidaridad otro valor de nuestra convivencia civilizada. Una vez más, no es posible saber qué país queremos si no abrimos el diálogo, dejando hablar a todos en este país, especialmente a los que hemos invisibilizado y a los marginados.

Dice Cortina (1998) que "hasta un pueblo de demonios" necesita reconocer mínimos de convivencia. Y eso no será posible si seguimos con un modelo oligárquico de país, cuyo poder excluye a los demás no solo del ejercicio del poder, sino de sus propias vidas.

El pluralismo como reconocimiento de nuestras diferencias también ha sido experiencia social y política, en otros tiempos. Recordemos al emperador indio Ashoka (s. III a.C.) que dio libertad a todas las religiones, porque su progreso también beneficiaba a las demás. Así, promulgaba: "Que todas las comunidades sean muy instruidas y tolerantes" (1987, p. 99). Experiencia de tolerancia religiosa también recordamos en la ciudad de Toledo (s. XII), donde convivieron pacíficamente cristianos, judíos y musulmanes, produciendo un esplendor cultural. Esto nos indica que, si antes fue posible la concordia entre comunidades diferentes, ¿por qué no lograrlo en nuestros días? Ver esas nuevas condiciones para el pluralismo es tarea tanto de eticistas como de intelectuales que apuestan a una mejor sociedad.

\section{UNA BASE EPISTÉMICA PARA EL PLURALISMO}

En la india antigua se ha hablado de acintyabhedābheda, que es la inconcebible unidad y diferencia, pues para algunas escuelas las diferencias permiten la unidad y la unidad da sentido a las diferencias. Hay pues una relación inherente entre unidad y diferencia. Otras escuelas como la del budismo y jainismo, utilizarán la metáfora de los ciegos y el elefante: cuando el rey manda decir a cada ciego qué es un elefante, los cuales solo habían tocado una parte del animal, entonces, uno dice que el elefante se parece a una cuerda (porque tocó solo la cola), otro dice que el elefante es como un tronco (porque tocó una pata), otro que el elefante es como una gran pelota (pues tocó la barriga), otro como un gran abanico (pues tocó la oreja), etc. De ese modo, la verdad última se nos escapa, por lo que necesitamos aprender las verdades de los demás para ir entendiendo la 
realidad. Solo cuando creemos (sean los individuos, los grupos o el Estado mismo) que ya tenemos la verdad última es que abrimos la puerta al conflicto violento y a la falta de respeto por la vida de los demás.

Y estas perspectivas necesitan ser aprendidas desde las instituciones educativas. Sin embargo, nuestras formas clásicas de educación han sido la del maestro que da su conferencia magistral, por lo que todos solo debieran escuchar. El maestro tiene la verdad, él sabe, por lo que todos debemos creerle. No cabe duda de que esta forma de educación no promueve el diálogo ni la evaluación de las ideas. Solo genera sujetos pasivos, que deben adaptarse a determinadas verdades. Por eso, se hace indispensable una educación intercultural, abierta a otros saberes que la academia excluye, no solo para enriquecer nuestras perspectivas, sino por ser una condición de una convivencia democrática.

\section{REFERENCIAS BIBLIOGRÁFICAS}

Cortina, A. (1998). Hasta un pueblo de demonios. Ética pública y sociedad. Madrid: Taurus.

Mill, J. S. (1997). Sobre la libertad. Madrid: Alianza Editorial.

\section{CITAR COMO:}

Polo Santillán, M. A. (2020). Democracia y pluralismo moral. Puriq, 2(1), 36-39. https://doi.org/10.37073/puriq.2.1.65 